\title{
ROMPIENDO LA JERARQUÍA DE LA MESA: EMULACIÓN SOCIAL, ALIMENTACIÓN Y MATERIALIDAD EN LA LITERATURA CATALANA BAJOMEDIEVAL
}

\author{
BREAKING THE HIERARCHY OF THE TABLE: \\ SOCIAL EMULATION, FOOD AND MATERIALITY \\ IN LATE MEDIEVAL CATALAN LITERATURE
}

\author{
Luis ALMENAR FERNÁNDEZ \\ Universitat de València \\ luisal5@uv.es
}

Resumen: Este artículo supone un acercamiento al fenómeno de la emulación social en el ámbito de la alimentación y los objetos que la rodeaban. Para ello se estudian algunas de las obras más representativas de Ramon Llull, Francesc Eiximenis y Vicent Ferrer, quienes criticaron fieramente la moral de los individuos corrientes y humildes que deseaban comer y beber como los ricos. A partir de las percepciones y consideraciones incluidas en sus escritos, se aborda qué aspectos de la alimentación de las élites podían reproducir las clases populares, cómo se difundían las modas alimentarias y por qué todo ello era tan duramente atacado por estos autores.

Palabras clave: emulación social, alimentación, materialidad, literatura catalana, Baja Edad Media
Abstract: This essay represents an approach to the phenomenon of social emulation as to feeding and the objects around it. Some of the most representative works by Ramon Llull, Francesc Eiximenis and Vicent Ferrer are studied for this purpose, for they fiercely criticized the moral of those ordinary and humble individuals that wished to eat and drink like the rich. Relying on the perceptions and statements contained in their writings, this essay addresses which aspects of the food of the elites could be reproduced by common people, how food fashions could spread, and why it all was so severely attacked by these authors.

Keywords: social emulation, food, materiality, Catalan literature, later Middle Ages 


\section{Introducción ${ }^{1}$}

Durante el curso de la Baja Edad Media la alimentación adquirió un papel esencial como indicador de estatus y posición social. Es conocido cómo la sociología de la alimentación estaba definida por una marcada «jerarquía de los alimentos», dado que los productos consumidos, su proceso de preparación y su presentación variaba profundamente de un sector social a otro. No obstante, se suele pasar por alto que esta jerarquía era, antes que nada, una «construcción mental», marcada por el acceso regular que los grupos sociales tenían a cada alimento (García Marsilla, 1993: 187). En la práctica, la jerarquía de la mesa podía flexibilizarse hasta, de hecho, romperse, dado que las clases populares podían emular los ritos alimentarios de los grupos privilegiados. Esto último lo sabemos porque diversos eclesiásticos de la época, autores de las más conocidas obras de carácter moralizante del período bajomedieval escritas en catalán, se dedicaron a atacar estos comportamientos, como Ramon Llull (1232-1315/1316), Francesc Eiximenis (1330-1409) y Vicent Ferrer (1350-1419). Llull y Eiximenis son especialmente conocidos entre los historiadores de la alimentación, dada la atención que le dedicaron como un ámbito de la vida que incitaba pecados como la gula y la codicia (Trias, 1996: 689-698; Trias, 1995: 845-856; Eiximenis, 1983). Su interés no era casual. Formaba parte de su preocupación por las nuevas realidades económicas y sociales que estaba comportando la naciente economía de mercado, entre ellas el rol central que adquiría la comida como un ámbito que reproducía las desigualdades sociales. De ahí que también escribieran, desde una postura reaccionaria, sobre temas como el crédito, el comercio, la riqueza o la misma idea del lucro personal, que chocaban con la moral y la ética cristiana más tradicional. La proliferación de este tipo de obras fue un fenómeno visible en el norte y el sur de la Europa bajomedieval desde el siglo XIV, coincidiendo así con el alto grado de comercialización que las sociedades occidentales estaban alcanzando, así como con la mejora de los niveles de vida y de la cultura material de las clases populares (Todeschini, 2005:

1 El autor es beneficiario de una ayuda postdoctoral de la Generalitat Valenciana y el Fondo Social Europeo (APOSTD19), y es miembro del grupo de investigación de excelencia CiSEM (Cultures i Societats de l'Edat Mitjana) de la Universitat de València. Este trabajo se inserta dentro del proyecto PROMETEO/2019/072 de la Generalitat Valenciana «Desigualdad económica y movilidad social en la Europa mediterránea (siglos XIII-XVI)», así como del proyecto «¿Crecimiento sin desarrollo? Distribución de la riqueza, movilidad social y acción política en la Europa mediterránea (siglos XIII-XV)», del Ministerio de Ciencia, Innovación y Universidades (PGC2018-099275-B-I00). 
151-230; Howell, 2010: 1-48; Petrowiste, 2018: 1-14; Furió, 2011: 17-56; Dyer, 2005: 132-139).

La emulación social, es decir, la imitación de los modos de vida de los grupos privilegiados por parte de las clases populares, ha de entenderse pues como una de esas nuevas realidades de la época. Como concepto se presenta inseparable de otros muchos profundamente enraizados en la sociología y en las ciencias sociales, como el de «distinción», «lujo» y «moda» (García Marsilla, 2019a: 14 y ss; De Vries, 2008: 46-47). Como realidad histórica, la emulación social constituye una de las explicaciones más recurridas para comprender muchos de los cambios en la cultura material del período bajomedieval. Es conocido cómo nuevos objetos cotidianos proliferaron entre las clases populares desde mediados del siglo XIV, y muchos de ellos eran productos tradicionalmente exclusivos, propios de las casas y hábitos de vida de los sectores más ricos y privilegiados (Furió, 2011: 37-50; García Marsilla, 2014: 227244; Dyer, 2005: 126-157). Esto es una muestra de que muchos de los grandes cambios en la realidad material de la mayor parte de la población pudieron tener una inspiración en las formas de vida de las clases altas, como revela, entre otras cosas, la proliferación en esta época de normativas suntuarias por todo el panorama europeo, así como de modas directamente inspiradas en las cortes reales o en las pautas de consumo que se desarrollaban en las grandes urbes (Martínez Martínez, 1991: 115-140; Mugueta y Osés, 2002: 107-118; Brouquet y García Marsilla, 2015; Muzzarelli y Campanini, 2003; García Marsilla, 2014: 227-244).

El objetivo de este trabajo es realizar un acercamiento a la emulación social en el ámbito de la alimentación y los objetos que la rodeaban a través de estos autores: ¿Hasta qué punto percibieron que las clases populares emulaban la cocina y la etiqueta de los grupos privilegiados? ${ }^{2}$ Con el fin de aproximar esta cuestión, este trabajo se divide en cuatro partes. La primera analiza la percepción de la alimentación y su materialidad como un ámbito de ostentación que pudiera imitarse. La segunda parte explora qué aspectos de la alimentación de las élites emulaban las clases populares y por qué las criticaban estos autores. La tercera estudia los valores, de prestigio o humildad, que se atribuyen a los enseres con los que se preparaban y servían los alimentos en estas

2 Se recurre concretamente a las obras que se citan a continuación, que constituyen algunas de las más utilizadas por los historiadores de la alimentación: Llull, 1972; Llull, 1982; Eiximenis, 1927; Eiximenis, 1983; Eiximenis, 1929-1932; Ferrer, 1971-1988. 
obras. Finalmente, la cuarta parte indaga sobre cómo se pudieron transmitir las modas alimentarias entre los diversos sectores de la sociedad medieval de manera que tal emulación fuera posible.

\section{La alimentación como distinción: contra golafres y curiosos menjadors}

Los escritores de la literatura moral en lengua catalana eran bien conscientes de que la alimentación servía de pretexto a los poderosos para realizar un alarde de su riqueza y honor de cara a sus iguales, por un lado, y frente al resto de la sociedad, por el otro. Sobre esto quien más escribió fue sin duda Francesc Eiximenis, en el tercer volumen de su obra monumental Lo crestià. Aquí el franciscano ataca recurrentemente al «rich hom aquell que menjava delicadament e vestia porpra e draps preciosos» (Eiximenis, 1929-1932: vol. 4, 229). Tal actitud no era sino una extensión del pecado de la gula, y por ello, quienes la llevaban a cabo aparecen definidos como golafres («glotones»). Estos desarrollaban un sentido de la etiqueta singular, pero no por puro placer, sino porque buscaban distinguirse de sus iguales. Golafres eran aquellos «qui ço que menjen no $u$ volen menjar axí com los altres ho menjen comunament» (Eiximenis, 1983: 84). A estos pecadores no les bastaba, por ejemplo, con beber mucho vino y de muy buena calidad, sino que estudiaban cuidadosamente la copa donde lo servían, si su material era el oro o la plata, y todo ello para que los incitara a beber más:

La quarta mala circunstància del peccat de gola sí és, apparellar la vianda massa curiosament e massa preciosa, axí com fan aquells qui ço que menjen no·u volen menjar axí com los altres ho menjen comunament, mas tostemps hi volen qualque specialitat en quinya que manera; car si los altres ho menjen en olla, ells ho volen en ast o en pa, o en caçola o en altra manera, e ço que los altres acostumen menjar ab una sabor, ells n'i volen quatre si fer-se pot. [...] No 1 ls basta beure molt vy e bo, ans encara estudien que lo vexell ab què 1 beuen sia bell e curiós e preciós qui 1 s provoch a més beure. (Eiximenis, 1983: 60)

Y es que el franciscano no tenía ningún reparo en criticar por esto no solo a los nobles y a los ricos burgueses, sino a los mismísimos reyes de la Cristiandad, a causa de sus exuberantes banquetes. En estas comidas, que se prolongaban durante días, tenía lugar un farragoso despliegue de suculentos y exóticos manjares, objetos singulares de oro y plata, que se acompañaban 
de bailes, músicos y sirvientes de lo más diversos (Riera, 2013: 65-100; Riera, 1995-1996: 181-205). Eiximenis consideraba esto una terrible abominación, que desprestigiaba las más dignas casas, porque era evidente que lo que buscaban los poderosos no era solo comer, sino dedicarse a «ensenyar lur magnificiència e a dilatar lur honor e preu e fama que no per neguna altra cosa»:

\footnotetext{
Per aquest peccat són huy desnostades moltes cases de prínceps en lo món, la taula dels quals era tan excesiva en quantitat e en multitut de molts me[n]jars e en qualitat de curiosos apparellaments que era abhominació a nostre senyor Déu, car despenien, aprés una missa que hagueren hoÿda, quaix tot lo jorn a estar en taula més a ensenyar lur magnificiència e a dilatar lur honor e preu e fama que no per neguna altra cosa. (Eiximenis, 1983: 87)
}

Si el servicio y el despliegue de los alimentos a la mesa aparecen considerados - y, en consecuencia, atacados- por ser un marcador intencionado de estatus, lo mismo puede apreciarse con la manera de preparar las comidas. Eiximenis también abominaba de la «cuyna de fumositats e de superfluitats» de las clases altas, que distinguía de la «cuyna comuna» de las clases populares (Eiximenis, 1929-1932: vol. 4, 175 y 234-235). Y es que la distinción también se buscaba en la cocina, haciendo que las cosas no supieran u olieran como normalmente lo hacían. Eiximenis arremetía también contra los curiosos menjadors, es decir, quienes «ço que los altres acostumen menjar ab una sabor, ells n'i volen quatre si fer-se pot» (Eiximenis, 1983: 84). Esto era algo fundamental, porque la dieta de las clases populares era mucho más monótona en ingredientes y en experiencias sensoriales que la de las clases altas, que podían permitirse el acceso a las especias, al azúcar y a otros productos de fines similares (García Marsilla, 2010: 111-125). Y así, estos personajes no se privaban de buscar nuevas técnicas culinarias, introduciendo nuevos artilugios y procesos que alteraran el sabor habitual de las viandas: «si los altres ho menjen en olla, ells [los curiosos menjadors] ho volen en ast o en pa, o en caçola o en altra manera» (Eiximenis, 1983: 84). Precisamente, los famosos libros de recetas de época bajomedieval, como el Llibre de Sent Soví o el Llibre del Coch, tenían como finalidad ser una especie de manual de cocina de vanguardia para los cocineros profesionales de los grandes nobles y burgueses, que pudieran satisfacer esta inquietud por la sorpresa y la distinción en las comidas (Llibre de Sent Soví, 2014; Nola, 2012). 


\section{Comiendo como ricos siendo pobres}

Con todo, la idea de llenar de sabor las comidas o de ornamentar ricamente las mesas, propia de reyes y de nobles, atrajo cada vez más a las clases populares. Esto se deduce de una variedad de críticas que estos autores realizaban en sus obras, y que se orientaban a dos cuestiones fundamentales. La primera era que anhelar ser como los ricos entraba en contradicción con los valores más básicos de austeridad y humildad que habían caracterizado la vida y virtudes de Jesús de Nazaret. Lo deseable y lo que había que anhelar era la pobreza, y no la riqueza. Lo venerable era tener una vida aspra, o sea, austera, mesurada, casta y pobre; y esta debía apreciarse en los aspectos que autores como el mallorquín Ramón Llull identificaban como signos fundamentales de riqueza personal: el comer, el vestir y el dormir («aspres viandes, aspre 1lit, aspres vestiments») (Llull, 1982: 139). En consecuencia, el apego a los bienes materiales que podía sentir un miembro del pueblo llano, como un artesano o un campesino, debía plasmarse en términos meramente funcionales. Así lo explica Vicent Ferrer en uno de sus sermones, en el que desglosa lo que ha de amarse en el mundo y el orden en el que hacerlo: primero Dios, luego el alma, luego el prójimo, luego la salud y, por último, los «béns mundanals». Estos debían amarse «axí com fa lo obrer los sturments a son offici. Lo notari ama la ploma, lo tinter, lo paper; lo laurador ame los bous, lo aradre, lo càvech; lo fuster, l'axa, la serra, lo escarpe, etc.; car sens aquells no porien obrar» (Ferrer, 1971-1988: vol. 3, 190-191). En definitiva, se recomendaba tener apego solo por las posesiones que fueran útiles para desempeñar el cometido de cada individuo en el seno de la sociedad feudal.

El segundo motivo de crítica hacia la imitación de las clases altas era mucho más sugerente. Los pobres que buscaban distinguirse de sus iguales comiendo y bebiendo como los ricos eran igualmente golafres, pero tal actitud era de una vileza muy superior, porque los pobres debían comportarse como tales. Esto se aprecia en un breve capítulo de Lo Crestià de Eiximenis, que trata, como bien expresivamente reza el título, sobre «aquells qui són pobres e volen viure e menjar curiosament» (Eiximenis, 1983: 92-93). Aquí se explica que ser pobre y no actuar como tal comportaba no poder ser correctamente identificado dentro de la jerarquía social, lo cual conllevaba muchos problemas. Eiximenis lo justificaba desde una óptica bastante condescendiente, argumentando que, si los pobres no mostraban su pobreza, los ricos no querrían darles limosnas y caridades: 
Lavors, ensenya l'om que és copiosament golafre cant ve que és pobre, e encara vol viure curiosament, e fa son poder de usar en son menjar e beure de les millors coses que troba, ne que pot haver. Aquesta és un[a] tan gran viltat que provoca [a] aquells qui $\cdot u$ ven de negar-los almoyna e tot benifet. (Eiximenis, 1983: 92-93)

Bajo esta argumentación subyacía un problema mucho mayor, y es que la imitación de las clases altas atentaba contra el orden natural de las cosas porque podía llevar a no poder distinguir al rico del pobre. Es por ello que, casi un siglo antes de Lo Crestià, Ramon Llull entendía la imitación del estilo de vida de las élites como un acto perverso y, literalmente, diabólico. El mallorquín lo ejemplificaba ni más ni menos que con la historia de Lucifer, dado que este había sido un ángel que, en lugar de sentirse complacido con su condición, se sentía superior al resto de seres celestiales. Tal sentimiento le había llevado a tratar de ascender hasta el nivel de su creador, que era Dios, quien a causa de esta ambición ilegítima acabó condenándolo a ser el señor de los infiernos. Llull extrapolaba esta historia para atacar la figura del pobre orgullós, un término que también utilizaba Eiximenis junto al de pobre delicat (Eiximenis, 1983: 67). Se trataba de personajes humildes con la avidez de ser iguales a las clases altas «en riquesa e en honrament». Esto era moralmente reprochable porque comportaba menospreciar a sus iguales, lo que subvertía el orden social pues el deseo de ascenso no acababa nunca: «si és ergullós e és sabater, tu volràs ésser draper; e con seràs draper, volràs ésser burguès; e con seràs burgès, volràs ésser cavaler; e de cavaler volràs ésser comte; e de comte a rey, e de rey a emperador. E si més podies pugar, més volrries puyar» (Llull, 1972: 152):

En aquest món home ergullós seguex la manera que $\cdot 1 s$ dimonis agueren con foren creats àngels; cor l'ome pobre ergullós desija ésser egual al rich home en riquesa e en honrament, e con és puyat a aquella riquesa e aquell honrament, mensprea aquell qui li és egual, e vol ésser sobre él en nobilitat e en riquesa, e desiga ésser egual a altre home qui li és desús en riquesa e en honrament; e enaxí no està en àls mas en voler puyar e en menysprear son egual. E per açò aytals hòmens són semblants als demoniis, qui menysprearen los àngels benignes en so que volgren ésser pus nobles que éls, en quant volgren ésser semblantz a Déu. (Llull, 1972: 151)

El peligro era, por tanto, que la emulación social se tradujera en verdadera promoción social y que los sectores populares lograran conquistar mejores escalafones en la pirámide de la sociedad feudal. Sin ser tan explícito como lo era Llull, Eximenis debía de compartir también esta preocupación, a juzgar por una crítica que realiza en Lo Crestià a los campesinos que se ordenaban sacerdotes 
no por devoción, sino para tener una vida más cómoda, de «bons menjars e fin vestit, e belles claustres e grans honors». Para el franciscano, estos campesinos estaban engañando a la sociedad (habían «enganat lo món»), pero también se engañaban a sí mismos, porque en el fondo seguían siendo campesinos, a pesar de haber cambiado su estilo de vida, su vestimenta, sus alimentos y tener mayores comodidades (Eiximenis, 1983: 67). Tal afrenta, sin embargo, no quedaba sin castigo, y quienes se atreviesen a instrumentalizar de forma tan banal el servicio a Dios podían esperar un importante vacío moral, que llevaba a no poder encontrar placer en ninguno de esos pequeños lujos:

Yo, pobre e rustical, en casa de mon pare amvides podia umplir lo ventre famolent de pa de mill; jamés no·y beguí quaix sinó aygua; lo meu lit era la pallaça sola; la mia companyia eren los bous e les ovelles; los meus negocis eran parlar e tractar de laurar e de cavar, de plantar e de regar, e de fems e de basses. Ara, despuys que só ecclesiàstich, no puch trovar sabor en negun pa fort; pochs són los vins qui $\cdot \mathrm{m}$ plàcien; mos vestirs són preciosos e mon lit emperial; disput de diversitats de menjars de carns e de peys, de salses e de fruytes; los reys condempne, los bisbes jutge, [e] los cavallers tinch per pajeses. De pajès no faç menció. (Eiximenis, 1983: 69) ${ }^{3}$

Con todo, las obras de Llull y Eiximenis fueron escritas para las élites de la sociedad. La condena a estos individuos humildes que se comportaban de manera acomodada podía ser dura y rotunda, puesto que no eran la audiencia de estos textos. Vicent Ferrer, un fraile dominico famoso en la Valencia y la Europa del siglo XV, tuvo una participación mucho más activa con el pueblo llano a través de sus sermones. En estos se reproducía el mismo mensaje, pero en un tono lógicamente más cándido e instructivo, que buscaba la receptividad del pueblo más de lo que podían hacer Llull o Eiximenis. Vicent Ferrer ilustraba su rechazo a la emulación social a través del caso de un hombre pobre que deseaba vestirse como un rico. En el sermón, el pobre se admiraba de los ropajes de otro individuo, que envidiaba profundamente: «O, tan ben vestit va aquell, ¿e yo no só fill de rich hom, que puch anar axí com aquell?». Ferrer, en este ejemplo, lo disuadía amablemente de sus intenciones, aludiendo de nuevo a la figura virtuosa del Cristo pobre: «Met la una orella sobre Jesuchrist. Pen-

3 Esta, en parte, es la versión suavizada de un topos literario conocido, que es el del campesino que asciende socialmente, comienza a comer alimentos impropios de su estatus, y acaba enfermando y, en ocasiones, muriendo. La anécdota aparece narrada entre diversos autores de Francia y de Italia, y también entre los escritos del propio Eiximenis, quien la aplicaba a un presunto rey de Rávena de origen campesino, quien solo se recuperó comiendo las gachas y las legumbres con las que había crecido (García Marsilla, 2013: 130-131). 
sa que ere pobre: «E yo deyg ésser pobre axí com aquell e per amor d'ell»»» (ambas citas en Ferrer, 1971-1988: vol. 3, 57).

El mensaje era hacer ver la pobreza como algo deseable, y no la riqueza. «Les riquees no les devem molt desigar», puede leerse en otra parte de estos sermones (Ferrer, 1971-1988: vol. 6, 103). Eiximenis también recomendaba la abstinencia y la templanza, evitando la «superfluïtat en menjar, beure, dormir, veure e oir» (Eiximenis, 1929-1932, vol. 4, 234-235). Con ello se pretendía desalentar a aquellos que querían vivir materialmente mejor y, en definitiva, se instaba a la aceptación del estatus social con el que se había nacido. La glorificación del conformismo y el rechazo a lo que hoy en día llamaríamos entrepreneurship, de hecho, es un elemento más en el pensamiento de estos autores en su lucha contra la emulación y la promoción social. El caso más ilustrativo es un sermón de Ferrer donde se habla de un labrador que anhela ser como un zapatero. La razón es que al campesino todo le iba mal, porque trabajaba mucho, no tenía hijos y no tenía buenas cosechas. El zapatero, en cambio, «tots diez enriquie», a pesar de trabajar a jornal y no tener propiedades. En la historia, el labrador le pregunta al zapatero cuál es su secreto. Este confiesa que posee un «tresor en un camp»; el campesino desea verlo y el zapatero accede a enseñárselo. Después de varios periplos no llegan al tesoro, porque el zapatero, de camino, para en una iglesia a escuchar misa, obligando al campesino a estar con él, se hace tarde y se vuelven a casa. Esto se repite durante varios días, hasta que el zapatero confiesa que su tesoro era, en realidad, esa asistencia diaria a misa, y que avanza en la vida con la ayuda de Dios. El campesino, por el contrario, había descuidado sus obligaciones cristianas al dedicar tanto tiempo a trabajar la tierra por querer prosperar en su explotación. La fórmula del bienestar estaba, pues, en el conformismo del zapatero y no en el trabajo duro del campesino:

«Sapiats que aquest és lo camp del tresor, que quiscun dia yo $\cdot y$ vinch, e per açò he ço que he mester. Mas vós haveu aquexes possessions e bestiars qui us occupen, e lexau lo serví de Déu, e per ço no podeu avançar res.» E d'aquí avant lo laurador hoí missa cada dia, e abundà en riquees. (Ferrer, 1971-1988: vol. 3, 103-104)

Con todo, estos autores no solo ayudan a identificar la existencia de un proceso de emulación social de la gastronomía de las élites, sino que ellos mismos pudieron haber sido influyentes a la hora de combatirla. No puede ser una coincidencia lo similar que es su lenguaje a los preámbulos de las normativas suntuarias que proliferaron desde el siglo XIV por la Península Ibérica y 
otros escenarios europeos, coincidiendo con la mejora de la cultura material de las clases populares (García Marsilla, 2015: 561-591, esp. 561-565; Muzzarelli y Campanini, 2003; Crouzet-Pavan, 2007). La normativa de 1345 de la ciudad de Valencia, la más antigua que se conserva de este lugar, se justificaba porque «les gents, per sugestió e engan del demoni e per mal ús, facen moltes vanitats e sobrefluitats, les quals desplaen a Déu e no-s fan a honor sua ne a profit del prö̈sme» (García Marsilla, 2015: 572-573). Estas leyes tenían el fin explícito de disuadir a las clases populares de las actitudes que podían implicar algún tipo de exhibición de los lujos asociados a los grupos privilegiados. Fueron promulgadas fundamentalmente por los grupos dirigentes de las grandes ciudades, con los que los autores de muchas de estas obras tenían una importante vinculación. Eiximenis quizás sea el caso más claro, pues dedicó algunas de sus obras a las autoridades municipales de la ciudad de Valencia. Del famoso Regiment de la cosa pública, por ejemplo, se disponía de un ejemplar en la sala de reuniones del consell y los jurats para su consulta, atado a una mesa con cadenas (García Marsilla, 2015: 575).

Aunque estas normativas son conocidas sobre todo por sus limitaciones al consumo textil, muchas afectaban también a aspectos relativos a la alimentación. Se legislaba sobre los banquetes de las bodas y aquellos organizados por las organizaciones confraternales, que tenían un marcado carácter popular, fijando el número de invitados, la calidad y cantidad de piezas de las vajillas de plata y también los alimentos servidos. Desde 1372, de nuevo en Valencia, se promulgaron prohibiciones del consumo de carne de ave en estos eventos, la más cara y exclusiva, que pronto se ampliaron a otros animales jóvenes de carne muy tierna, como la ternera, el cabrito y el cochinillo. El uso de vajillas de plata, además, quedaba restringido a las bodas y al cubierto de la novia (García Marsilla, 2015: 585).

\section{La materialidad de la alimentación y sus valores culturales}

Si los alimentos, las técnicas culinarias y las maneras a la mesa podían ser emuladas, los objetos involucrados en estos procesos no se quedaban al margen. Esta literatura aporta ideas sobre lo que pudo ser el significado cultural de ciertos enseres vinculados a la alimentación, algunos de ellos con claras atribuciones «de clase». De hecho, puede apreciarse una «jerarquía de dignidades» bastante congruente con la propia «jerarquía de la mesa», pero con matices muy sugerentes. 
Las vajillas de plata y oro aparecen en estas obras asociadas a los más altos valores de honor y de prestigio. Ramon Llull las consideraba ya en el siglo XIII directamente a la altura de las joyas, por ejemplo, cuando refería al modo de vida de los nobles, hablando de sus «copes d'aur e d'argent e les altres joies de què ornen lus taules e umplen llurs caixes» (Llull, 1982: 239-240). Tiempo después, Vicent Ferrer hablaba sobre las virtudes de la plata explicando que, en cuanto a dignidad, estaba a medio camino entre el plomo y el oro, materiales de los que se hacían los «calzes e taces», de manera que podía considerarse que recibía una virtud de cada uno: «del plom sofisticació, e de l'or dignitat» (Ferrer, 1971-1988: vol. 5, 151). En cualquier caso, tanto el oro como la plata reciben también críticas en estas obras, pues aparecen asociadas a la ostentación como una actitud perniciosa que estimulaba multitud de pecados. En los sermones de Vicent Ferrer, por ejemplo, se define la avaricia como la voluntad de «sostener honors, ben mengar, ben beure, bona cavalcadura, vexella d'argent» (Ferrer, 1971-1988: vol. 4, 74). En otra ocasión, el mismo autor refiere al pecado de la vanidad, ejemplificándolo con el caso de un alto dignatario eclesiástico que tenía una vida de gastos desenfrenados, explicando que «tant són los encontinaments e los cavalls e mules e vexella d'argent e de or, e vestís e forradures, que la renda no $y$ baste» (Ferrer, 1971-1988: vol. 5, 147). En los escritos de Llull, por otro lado, la ostentación de la riqueza a través del oro y la plata aparece ridiculizada en una anécdota en la que un cardenal se arrodilla delante de una mujer «tota ornada d'aur e d'argent e de pedres precioses» con el fin de avergonzarla, diciendo que lo hacía porque «era semblant a ídola» (Llull, 1982: 239).

En contraste con los metales preciosos estaban los materiales que no expresaban honor ni prestigio pues, de hecho, se vinculaban con valores opuestos. Los utensilios de madera, por ejemplo, son identificados con ideas de pobreza y humildad. El ejemplo más claro está en una metáfora de Vicent Ferrer en la que argumentaba que Dios intenta sacar lo mejor de todas las personas, pero no todas son igualmente receptivas a su mensaje. Para explicarlo ponía el caso de cuatro platos llanos (talladors), fabricados de oro, plata, estaño y madera. Todos pueden exponerse a la luz del sol, pero nunca brillar con la misma intensidad debido a la naturaleza del material. El brillo, en efecto, es más moderado conforme disminuye la dignidad del material del plato, hasta llegar al ejemplar de madera, cuya capacidad de reflejar la luz del sol es nula (Ferrer, 1971-1988: vol. 4, 109-110).

Ahora bien, y por mucho que se denostaran como indignas estas vajillas de madera, en la práctica podían ser aceptables incluso para reyes y nobles. Los 
privilegiados no siempre utilizaban los metales preciosos en las comidas cotidianas, particularmente cuando no era necesario mostrar el prestigio familiar. Prueba de ello es que las vajillas de plata eran empeñadas de manera recurrente cuando no iban a utilizarse. Esta fue una práctica común entre la nobleza bajomedieval europea, apreciable en la Corona de Aragón en el caso de monarcas como Alfonso el Magnánimo, o de nobles como los duques de Gandía (García Marsilla 2010: 153; García Marsilla, 1996-1997: 33-47; Conde, 2000: 185-196). Mientras tanto, la nobleza podía recurrir a las vajillas de madera con naturalidad, siendo conscientes de que no era un material digno de su posición. Esto se aprecia en una carta ni más ni menos que del rey Pedro el Ceremonioso, quien solicitaba que se recuperara con urgencia la vajilla de plata empeñada de la corte porque se necesitaba para una futura comida de Navidad, a la cual iban a asistir personalidades destacadas del reino de Francia. «En altra manera», afirmaba el monarca, «en grant vergonya poríem venir» (Fontbona y Soberanas, 1991: 172, n. 16):

Lo rey d'Aragó. Manam-vos expressament sots pena de la nostra mercé que tot aquell argent o vexella nostra que és empenyora en poder d'En Jaume Oliver o de qualsevol altres persones tràscats e quítets, e aquells nos tramétats de continent, per tal manera que l'hajam per a festa sens faylla o triga, que en altra manera en grant vergonya poríem venir, que entre altres coses nos fallen tayladors d'argent, que no n'avem si no.1 nostre. E quant convidam null hom de recapte han li a portar la vianda en tallador de fust. E com nos siam en loch on nos venen fer reverència molts del Regne de Ffrança, per ço $u$ volem ne soffrerriem que per mal recapte vostre en les dites festes de les dites coses fossem envergonyits. (Fontbona y Soberanas, 1991: 172, n. 16)

La madera era, por tanto, inaceptable de cara a las grandes ocasiones al menos en lo que concernía al cubierto del rey, de la familia real y de los invitados principales, pero aun así se podía encontrar en uso entre sirvientes y comensales de rango más modesto. En los libros de cuentas de una serie de viajes que realizó la reina María de Luna en 1403, por ejemplo, constan grandes compras de platos «per servir en palau les dones e donzelles» (García Marsilla, 2018: 23, n. 86). Unos años antes, en un evento tan importante como el banquete de la coronación de Martín el Humano, que tuvo lugar en 1399, se encargaron 20.000 platos hondos (escudelles) y 16.000 platos 1lanos (talla-

4 Originariamente en Olivar, 1950. La carta original se conserva en el Archivo de la Corona de Aragón (Reg. 1.123, f. 648). 
dors) de madera, seguramente para los asistentes de menor rango (Fontbona y Soberanas, 1991: 173).

Si en el caso de la plata y la madera las valoraciones de estos autores pueden parecer poco sorprendentes, el caso de otros materiales llama más la atención por la difusión que alcanzaron durante el período bajomedieval. La cerámica de mesa, por ejemplo, aparece considerada con una dignidad igualable a la de la madera, es decir, como un producto ordinario, austero y humilde. Así lo ilustra un sermón de Vicent Ferrer al hablar de San Valero, obispo que renunció a su cargo y a todas sus riquezas con el fin de poder acercarse al pueblo. La sobriedad a la que había consagrado su nueva vida se hacía visible en no comer rodeado de plata durante las comidas, como correspondía a su anterior estatus, sino de madera y, además, de cerámica. Según Ferrer, «quan se dinave a sa taula, no $y$ tenie argent, sinó una cullera chiqua, mas terra o fusta [...] O, quinya humilitat!» (Ferrer, 1971-1988: vol. 3, 154).

A la cerámica se le atribuye en este pasaje, pues, una dignidad incompatible con el estilo de vida de los privilegiados. Esta idea se repite en otros autores, como Francesc Eiximenis. Este destacaba la cerámica dorada, producida en la villa de Manises mediante la técnica del reflejo metálico, como una de las maravillas del mismo reino de Valencia. En un conocido pasaje introductorio del Regiment de la cosa pública explicaba que «lo papa e los cardenals, e los prínceps del món [...] stant maravellats que de terra se puixa fer obra axí excel·lent e noble» (Eiximenis, 1927: 32-33). Lo llamativo, según Eiximenis, no era solo la belleza de las piezas decoradas en dorado, sino que esta se alcanzara mediante un producto fabricado «de terra». La cerámica no aparece considerada entre estos autores, por tanto, como un material apropiado para las clases altas per se. No obstante, podía elaborarse tanto y causar un efecto tan sorprendente que, en la práctica, podía atraer su atención. Y es que en lo que refiere a la materialidad de la alimentación, la emulación social se plasmó en este tipo de enseres, caracterizados por su fragilidad y amplias posibilidades estéticas, que permitían expresar connotaciones lujosas a pesar de ser ampliamente asequibles. Se ha dicho que las cerámicas doradas que proliferaron por los hogares de las sociedades del Mediterráneo, de hecho, imitaban las vajillas de oro y plata de las élites europeas (Goldthwaite, 1989: 1-32). Bienes de estas características han sido denominados historiográficamente como bienes de lujo popular o populuxe y, de hecho, han sido identificados como una pieza clave en las llamadas «revoluciones del consumo» a lo largo de la época preindustrial (Fairchilds, 1994: 228-248). 
El caso de la cerámica es el más conocido, pero no el único, ya que entre estos bienes de lujo popular habría que incluir también al vidrio, muy apreciado en la época por las posibilidades estéticas que ofrecía la maleabilidad del material. El vidrio siguió un proceso parecido de difusión entre los grupos populares al menos desde finales del siglo XIV (Capellà, 2015; Riu, 2008: 8387; Veeckman, 2002). ¿Qué consideración recibe el vidrio en estas obras literarias? En los pocos casos en los que se habla de este material, en general, se hace en positivo, elogiando su transparencia natural como una virtud. Esto era algo que pocos materiales podían lograr en el período medieval, y que se convirtió en una cualidad apreciada sobre todo a la hora de degustar las bebidas para conocer su calidad. La única referencia que hemos podido encontrar es una brevísima mención de Eiximenis al hablar de los vinos en mal estado, que podían confundirse con los vinos blancos y dulces porque amarilleaban en los vasos:

No t'esguarts lo vy cant tot grogueja en la taça daurada, o cant veuràs la sua color resplandir en lo bell e net vidre, car deus pensar que lo vy que axí està és un gran traÿdor, car fa bella cara defora e appar tot blan e dolç cant entra dins, mas a la fi, cant dins sia, ell te mordrà axí com a serp mortal e enveninada fins a la mort de la tua ànima, e encara de ton cors e de ta fama, axí com damunt és largament dit. (Eiximenis, 1983: 61)

Sabemos por otras fuentes, no obstante, que este material alcanzó una popularidad inmensa en el transcurso de la Baja Edad Media incluso entre las clases altas. A principios del siglo XVI, el Mestre Robert afirmaba en el Llibre del coch, uno de los más célebres libros de cocina catalanes, que los nobles preferían el vidrio sobre la plata como material para sus copas. Al dar indicaciones sobre cómo servir la bebida de manera apropiada, expresaba abiertamente que «realment crech que qualsevol senyor deu mas amar beure $a b$ vidre que no ab argent, perquè lo vidre, majorment aquell que és de selicorn, no se'n porie e'nenguna manera emmetginar», es decir, que no se le podía añadir veneno («metgines») a la bebida: «e vet así la rahó perquè los grans senyors amen més beure en vidre que no e nenguna altra cosa» (Nola, 2012: 31).

5 Sirva como ejemplo de la difusión que alcanzó el vidrio entre las clases populares los inventarios de bienes de labradores de Cataluña y Mallorca transcritos en Benito (en prensa), y Barceló (1994). 


\section{La transmisión de las modas en los ritos alimentarios}

Compartieran las clases populares estos valores o no, si estas imitaban las prácticas culinarias y la etiqueta de los privilegiados, tal y como revelan estos autores, debía de existir un proceso de transmisión en tanto que modas. Explicar cómo se difundían las modas en los ritos alimentarios es mucho más complicado que en el caso de otros ámbitos, como el vestido y sus complementos, que es el tema con el que se suele asociar el estudio de la moda. Los privilegiados - y entre ellos los mismos monarcas_-, escogían cuidadosamente sus prendas para exhibirlas en actos políticos e institucionales, invirtiendo enormes fortunas en una imagen personal que las clases populares podían conocer con facilidad (García Marsilla, 2019b: 151-167). Los contextos sociales más comunes de la alimentación y los objetos que la rodeaban, por el contrario, se desarrollaban en el ámbito privado, en el seno del hogar, siendo más difícil el poder observarlos. Con todo, existen diversas maneras mediante las que las clases populares podrían haber visto estos enseres en pleno funcionamiento, a juzgar por algunas referencias en las obras de los autores estudiados. Los sirvientes de los privilegiados y las clases acomodadas, por ejemplo, conocían sobradamente estos objetos, que limpiaban y guardaban a diario. Vicent Ferrer menciona en un sermón que, tras los banquetes, los criados domésticos acudían a la mesa a recoger los platos y las sobras, para luego comérselas ellos mismos:

En aquest sermó he pensat que tenga la manera que tenen pobres servidors en casa de algun senyor on servexen, que quan lo senyor ha mengat e finit lo dinar, vénen los pobres servidors e prenen los cantells de les taules, cerque què puxen mengar. (Ferrer, 1971-1988: vol. 6, 159)

Pero incluso los más pobres y humildes sin relación directa con personajes acomodados podían conocer la gastronomía de las élites, cuando pedían las sobras de los banquetes en las puertas de sus palacios y grandes casas. Era recomendable que los mismos privilegiados buscaran esta práctica para la purga de su alma de cara a la vida próxima. En ese sentido, Eiximenis aconsejaba que las primeras porciones que salieran de ollas y espetos fueran directamente a los que pedían limosna:

Tantost com sies en taula te n'aja lo cor que la primera cosa que hix de l'ast o de la olla sia partida axí que la primera porció baja a Déu, ço és, als pobres, e majorment e amagadament als vergonyats. (Eiximenis, 1983: 106) 
En una de sus recurridas críticas a la glotonería también disuadía al lector de ingerir y lamer hasta la última gota de caldo de las escudillas, porque era preferible dejar las sobras para los más necesitados:

Nuyl temps no entres tan pregon en la escudella que vingues a fregar-la per res del món, ans ne lexa queucom per amor de Déu e dels pobres e per bon nodriment. (Eiximenis, 1983: 122)

Las clases populares podían conocer así los manjares de los ricos, sin necesidad de entrar en sus viviendas. Los alimentos se les proporcionaban como limosna fuera del hogar, depositándolos en sus propios platos traídos de casa. Esta última práctica la recoge Ramon Llull en Evast e Blanquerna, en la descripción de la boda que un draper rico había organizado para desposar a su hija con un caballero. A la puerta de la casa se agolpaban «molts pobres qui esperaven que hom los faés almoina del romanent de ço qui roman a la taula», para lo cual cado uno había acudido con su propia escudilla para los alimentos y con una copa para el vino:

Con fo hora e temps que tots aquells de l'alberg hagren menjat, aportà hom lo relleu de la taula als pobres. Cascun pobre hac sa escudella, son anap, on reebés ço que hom li donava per amor de Déu. Evast no hac en què reebés les cols que hom li volia donar, ni no hac anap ni selló en què metés lo vi, e pregà un pobre que, per amor de Déu, li plagués que en la sua escudella e en lo seu anap reebés la seua part [...] Molt foren lo draper e tots los altres meravellats de la humilitat d'Evast. (Llull, 1982: 60)

Acceder al espacio privado de las clases altas o interactuando con él de diferentes maneras podía comportar así conocer su gastronomía. Esto era el primer escalón en la transmisión de las modas en el comer. Ahora bien, ¿cómo se difundían estas prácticas entre los diferentes estratos de la sociedad medieval? Desde luego, si se aspiraba a reproducir estas comidas hacía falta adquirir los enseres involucrados en esta cocina de alta alcurnia, como los espetos para los asados y las ollas para las salsas, o las mismas piezas de cerámica donde servirlas. En estas cuestiones, el mercado de segunda mano cumplió un papel central (García Marsilla, 2019a: 14). En la Corona de Aragón, en los llamados encants o almonedes, se concentraban a un precio más asequible bienes que procedían de las casas de todo el espectro social, de nobles, notarios y grandes mercaderes, y entre sus compradores no faltaban miembros del pueblo llano, como los artesanos de las grandes urbes, pero también los campesinos de sus inmediaciones (García Marsilla, Navarro Espinach y Vela Aulesa, 2015: 312- 
316). A partir de ahí, la difusión de estas prácticas culinarias hubo de ser mucho más rápida, entre sectores sociales entre los que las relaciones sociales y económicas eran mucho más fluidas.

En relación con esto último, acceder como invitado a una vivienda, fuera por amistad o interés, cobraba una importancia fundamental. Las comidas de sociabilidad, o eventos como bodas y celebraciones populares, debieron de constituir así el mecanismo final y más fundamental de difusión de las modas en el comer entre los humildes. Los antropólogos de la alimentación destacan la importancia de los food events, de las comidas como «instrumentos de diplomacia social», que cumplen una función de representación atractiva a todas las clases sociales (Douglas e Isherwood, 1979: 88-89). No debe ser una coincidencia que Francesc Eiximenis recomendara invitar a menudo a comer a casa a aquellos «on senyoria has, e, lla on no la has». Esta parte de su obra, el conocido «Com usar bé de beure e menjar» del tercer volumen de Lo Crestià, ha de entenderse en sí misma como un manual de instrucciones para asegurar una comensalidad propicia a los objetivos deseados. Ello constituye una muestra de la preocupación por el buen trato a estos invitados a quienes había que causar una buena sensación, por lo que era muy importante mostrar buen gusto y buenos modales en las comidas. Eiximenis recomendaba, por ejemplo, compartir con los invitados el tallador, el plato llano de uso común del que todos los comensales cogían la comida con las manos, acción que suponía un gesto de amistad y cercanía muy intensa. De hecho, esta cualidad del tallador hizo que el franciscano recomendara a los maridos compartirlos con sus mujeres como señal de respeto. En cambio, opinaba que era mejor que los hijos tuvieran un plato propio, separado del de los padres, para evitar que pensaran que estaban al mismo nivel:

Tostemps serva honor a ta muller que meng ab tu en un tallador, e la convida del millor si és fembre de bé, car tostemps te'n amarà e te'n prearà més. Null temps mengs en un tallador ab tos infants ne ab ton servent, mas ten-los en humiltat e sots tu matex axí que t'hajen en reverència. (Eiximenis, 1983: 108)

\section{Conclusión}

Llull, Eiximenis y Ferrer eran conscientes de que la alimentación podía instrumentalizarse para mostrar riqueza y honor, tanto en la presentación 
como en el sabor de los alimentos. Esos «pobres orgullosos» que tanto criticaban tenían mecanismos mediante los cuales podían conocer la gastronomía de los privilegiados, desde trabajar para ellos como sirvientes en sus palacios a recibir sus limosnas a las puertas de los mismos. A partir de ahí, estos grupos sociales debieron de atreverse a cocinar y comer como ellos. Era entonces, al romperse la jerarquía de la mesa, cuando surgía la abominación. La preocupación de estos autores por una sociedad glotona marcada por el pecado de gula y la avaricia enmascaraba, pues, algo mucho más inquietante: que no fuera posible distinguir a los ricos de los pobres. Y lo que era aún peor, que estos no solo se comportaran como ricos, sino que acabaran accediendo a sus posiciones, de manera que la emulación se convirtiera en promoción social, y que la sociedad feudal desapareciera tal y como la conocían.

La relevancia del pensamiento de estos autores solo hay que verla en su probable influencia en las normativas suntuarias, que frenaban de manera legal esos comportamientos que tanto les alarmaban no solo en las modas en el comer, sino también en el vestir. Con todo, estamos lejos de comprender completamente la relevancia de la emulación social en los grandes cambios en la cultura material y la vida cotidiana de las clases populares. El estudio de estos autores permite constatar que existían actitudes emulativas en la alimentación y su materialidad y entender el porqué de las críticas hacia esta. Conocer su relevancia social, constatando los aspectos concretos en los que la alimentación se manifestaba, es algo mucho más complejo. Y es normal, porque es más fácil conocer cómo se originaban las modas entre las élites que rastrear cómo se difundían entre las clases populares. Se hace necesario así investigar la difusión de enseres, prácticas y modos de vida concretos, a partir de la combinación de fuentes documentales de tipo muy diverso.

En cualquier caso, y como apunte final, habría que precisar que la emulación social fue solo una de entre las muchas fuerzas conductoras de los cambios en las actitudes de consumo que experimentaron las clases populares en el otoño de la Edad Media. Y, además, tampoco hay que olvidar que, incluso si se emulaba, también se asimilaba: habrá que intentar comprenden cómo esos nuevos hábitos se incorporaban al estilo de vida y a la cotidianeidad del grueso de la sociedad medieval y, ante todo, aspirar a entender qué se buscaba con ello. 


\section{Referencias}

\subsection{Edición de fuentes}

EIXIMENIS, Francesc [1983], Com usar bé de beure e menjar. Normes morals contingudes en el «Terç del Crestià». Edición de Jorge García. Barcelona, Curial.

EIXIMENIS, Francesc [1929-1932], Terç del crestià. Edición de Martí de Barcelona y Feliu de Tarragona, 4 vols. Barcelona, Barcino.

EIXIMENIS, Francesc [1927], Regiment de la cosa pública, edición de Daniel de Molins de Rei. Barcelona, Barcino.

FERRER, Vicent [1971-1988], Sermons. Edición de Gret Schib, 6 vols. Barcelona, Barcino.

Llibre de Sent Soví [2014], Edición de Joan Santanach. Barcelona, Barcino.

LLuLl, Ramon [1982], Llibre d'Evast e Blanquerna. Edición de Salvador Galmés. Barcelona, Edicions 62.

LLULL, Ramon [1972], Doctrina pueril. Edición de Gret Schib. Barcelona, Barcino.

NolA, Robert de [2012], Llibre del coch. Tractat de cuina medieval. Edición de Veronika Leimgruber. Barcelona, Clàssics Curial.

\subsection{Referencias bibliográficas}

BARCELÓ CRESPÍ, Maria (1994), Elements materials de la vida quotidiana a la Mallorca baixmedieval (part forana). Palma, Institut d'Estudis Baleàrics.

BENito I Monclús, Pere (en prensa), «Casa rural y niveles de vida en el entorno de Barcelona a fines de la Edad Media.» En Antoni Furió y Ferran Garcia-Oliver, eds., Pautes de consum i nivells de vida al món rural medieval, Valencia, Publicacions de la Universitat de València. Disponible en red: https:/www.uv.es/consum/ benito.pdf Última consulta: 01/12/2019.

Brouquet, Sophie y García MARsilla, Juan Vicente, eds. (2015), Mercados del lujo, mercados del arte. El gusto de las élites mediterraneas en los siglos XIV y XV. Valencia, Publicacions de la Universitat de València.

CAPEllà GalmÉs, Miquel Àngel (2015), Ars vitraria. Mallorca (1300-1700). Palma, Edicions UIB.

Coll ConesA, Jaume (2009), La cerámica valenciana. Apuntes para una síntesis. Valencia, Asociación Valenciana de Cerámica.

CONDE Y DElGAdo DE MolinA, Rafael (2000), «Orfebrería impignorada por Alfonso el Magnánimo en Nápoles en 1421», Aragón en la Edad Media, 16: 185-196.

Crouzet-PAVAN, Élisabeth (2007), Renaissances italiennes (1380-1500). París, Albin Michel.

Douglas, Mary e IsHeRwood, Baron (1979), The world of goods. Towards and anthropology of consumption. Nueva York, Basic books. 
DYER, Christopher (2005), An age of transition? Economy and society in England in the later Middle Ages. Oxford, Clarendon Press.

FAIRCHILDS, Cissie (1994), "The production and marketing of populuxe goods in eighteenth-century Paris.» En John Brewer y Roy Porter, eds., Consumption and the world of goods. London, Routledge: 228-248.

FONTBONA, Francesc y SOBERANAS, Amadeu, eds. (1991), Obra dispersa: llibre en homenatge al seu 90 aniversari. Barcelona, Biblioteca de Catalunya.

FURIÓ, Antoni (2011), «Producción, pautas de consumo y niveles de vida. Una introducción historiográfica.» En Esther López Ojeda, ed., Comer, beber, vivir: consumo y niveles de vida en la Edad Media hispánica. XXI Semana de Estudios Medievales. Logroño, Instituto de Estudios Riojanos: 17-56.

GARCÍA MARSILlA, Juan Vicente (2019a), «El lujo: ¿motor del crecimiento o camino hacia la ruina? Percepciones y actitudes ante el gasto suntuario en la Historia», Ars \& Renovatio, 7: 6-26.

GARCÍA MARSILlA, Juan Vicente (2019b), «El traje nuevo del rey. Los proveedores italianos de la corte de Alfonso el Magnánimo.» En Alexandra Beauchamp, ed., Acoger, abastecer y financiar la corte. Las relaciones entre las cortes ibéricas y las sociedades urbanas a finales de la Edad Media. Valencia, Publicacions de la Universitat de València: 151-167.

GARCÍA MARSILLA, Juan Vicente (2018), «Food in the accounts of a travelling lady: Maria de Luna, Queen of Aragon, in 1403», Journal of medieval history, 44: 1-26.

GARCÍA MARSILlA, Juan Vicente (2015), «Ordenando el lujo. Ideología y normativa suntuaria en las ciudades valencianas (siglos XIV y XV)», Sophie Brouquet y Juan Vicente García Marsilla, eds., Mercados del lujo, mercados del arte. El gusto de las élites mediterraneas en los siglos XIV y XV, Publicacions de la Universitat de València, Valencia: 561-591.

GARCÍA MARSILla, Juan Vicente (2014), «El lujo cambiante. El vestido y la difusión de las modas en la Corona de Aragón (siglos XIII-XV)», Anales de historia del arte, n. ${ }^{\circ}$ extra, 24: 227-244.

GARCÍA MARSILlA, Juan Vicente (2013), «Alimentación y salud en la Valencia medieval. Teorías y prácticas», Anuario de estudios medievales, 43/1: 115-158.

GARCÍA MARSILlA, Juan Vicente (2010), La taula del senyor duc. Alimentació, gastronomia i etiqueta a la cort dels ducs reials de Gandia. Gandia, CEIC Alfons el Vell.

GARCÍA MARSILlA, Juan Vicente (1996-1997), «El poder visible: demanda y funciones del arte en la corte de Alfonso el Magnánimo», Ars longa: cuadernos de arte, 7-8: 33-47.

GARCÍA MARsilla, Juan Vicente (1993), La jerarquía de la mesa. Los sistemas alimentarios en la Valencia bajomedieval. Valencia, Diputación de Valencia.

García Marsilla, Juan Vicente, NaVArro Espinach, Germán y Vela Aulesa, Carles (2015), «Pledges and auctions: the second-hand market in the late medieval Crown of Aragon.» En Il commercio al minuto. Domanda e offerta tra economia 
formale e informale (sec. XIII-XVIII). Atti 46 a Settimana di Studi di Prato. Florencia, Istituto Storia Economica F. Datini: 295-317.

GoldTHWAITE, Richard (1989), «The economic and social world of Italian Renaissance maiolica», Renaissance quarterly, 42: 1-32.

Howell, Martha (2010), Commerce before capitalism in Europe, 1300-1600. Cambridge, Cambridge University Press.

MARTíNEZ MARTíNEZ, María (1991), «Los gastos suntuarios de la monarquía castellana: aproximación a los aspectos técnicos y económicos a través del ejemplo de Juan I.» En Maria Barceló, ed., La manufactura urbana i els menestrals (ss. XIIIXVI). IX Jornades d'Estudis Històrics Locals. Palma, Govern Balear: 115-140.

MuguetA, Íñigo y OsÉs, Mercedes (2002), «Gastos suntuarios de Juana II y Felipe III de Evreux (1328-1330).» En Carmen Erro e Íñigo Mugueta, eds., Grupos sociales en Navarra. Relaciones de derechos a lo largo de la Historia. Actas del V Congreso de Historia de Navarra. Pamplona, Eunate: 107-118.

MuzZARElli, Maria Giuseppina y CAMPANINI, Antonella, eds., (2003), Disciplinare il lusso: la legislazione suntuaria in Italia e in Europa tra Medioevo edetá moderna. Roma, Carocci.

Olivar, Marçal (1950), La vajilla de madera y la cerámica de uso en Valencia y en Cataluña durante el siglo XIV (según los inventarios de la época). Valencia, Patronato José María Quadrado.

Petrowiste, Judicaël (2018), «Consommateurs et marchés locaux à la fin du Moyen Âge: un état de la question.» En Judicaël Petrowiste y Mario Lafuente, eds., Faire son marché au Moyen Âge. Méditerranée occidentale, XIII $-X V I^{e}$ siècle. Madrid, Casa de Velázquez: 1-14.

RIERA MELIS, Antoni (2013), «Gastronomía y política en los banquetes cortesanos de la Baja Edad Media.» En Manuel García Guatas, Elena Piedrafita y Juan Barbacil, coords., La alimentación en la Corona de Aragón (siglos XIV y XV). Zaragoza, Institución Fernando El Católico: 65-100.

RIERA MELIS, Antoni (1995-1996), «Jerarquía social y desigualdad alimentaria en el Mediterráneo Noroccidental en la Baja Edad Media. La cocina y la mesa de los estamentos privilegiados», Acta historia et archaeologica mediaevalia, 16-17: 181-205.

RIU DE MARTín, M. ${ }^{a}$ del Carmen (2008), «La manufactura del vidrio y sus artífices en la Barcelona bajomedieval», Anuario de estudios medievales, 38/2: 585-609.

TODESCHINI, Giacomo (2005), «La riflessione etica sulle attività economiche.» En Roberto Greci, Giuliano Pinto y Giacomo Todeschini, eds., Economie urbane ed etica economica nell'Italia medievale. Roma, Laterza: 151-230.

TRIAS MERCANT, Sebastià (1996), «Alimentació i dietètica a la literatura lul·liana.» En La Mediterrània, àrea de convergència de sistemes alimentaris (segles V-XVIII). XIV Jornades d'Estudis Històrics Locals, Palma, del 29 de novembre al 2 de desembre de 1995. Palma, Institut d'Estudis Baleàrics: 689-698. 
TRIAS MERCANT, Sebastià (1995), «La cuina lul·liana: criteris dietètics i nivells socials.» En Primer col-loqui d'història de l'alimentació en la Corona d'Aragó. Vol. 2, Actes. Lleida, Institut d'Estudis Ilerdencs: 845-856.

VEECKMAn, Johan, ed., (2002), Majolica and glass: From Italy to Antwerp and beyond. Ambees, Stad Antwerpen.

VRIES, Jan de (2008), The industrious revolution. Consumer behavior and the household economy, 1650 to the Present. Cambridge, Cambridge University Press. 